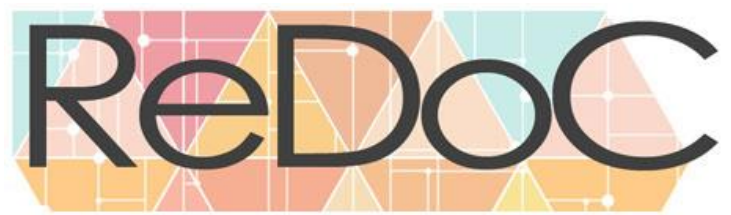

Revista Docência e Cibercultura

\title{
O SILENCIAMENTO DO SUJEITO TRAVESTI NA LEGISLAÇÃO
}

\author{
THE SILENCING OF THE TRANSVESTITE INDIVIDUAL IN THE LAW
}

\section{EL SILENCIO DEL SUJETO TRAVESTI EN LA LEGISLACIÓN}

\author{
Jaqueline Angelo dos Santos Denardin ${ }^{1}$
}

\section{RESUMO}

Neste trabalho, a partir da perspectiva teórica da Análise de Discurso (PÊCHEUX, 1969, 1975), temos como proposta analisar os efeitos de sentidos produzidos pela Lei $\mathrm{n}^{\circ}$ 11.340/2006, Lei Maria da Penha, a qual traz em seu texto considerações que permitem a aplicabilidade desse instrumento social normativo aos sujeitos Trans (transexuais e transgêneros) e o Projeto de Lei $n^{\circ}$ 8.032/2014, de Jandira Feghali, que amplia a proteção para esses sujeitos. Objetivamos refletir acerca do modo como questões relativas aos gêneros e às sexualidades são colocadas em funcionamento no discurso jurídico e dizem não só a respeito da mulher cisgênera, como também da mulher trans, embora a travesti seja nessas legislações apagada/silenciada. Nossa finalidade, com esta proposta, é perceber como a Lei e o Projeto de Lei compreendem e definem "orientação sexual", "gênero", "mulher", "transexual" e "transgênero", analisando como o discurso jurídico pode, muitas vezes, impor silenciamentos - neste caso com os travestis - aos sujeitos, mais do que garantir seus direitos.

PALAVRAS-CHAVE: Lei Maria da Penha; Projeto de Lei no 8.032/2014; Silenciamento da travesti.

\begin{abstract}
In this work, from the theoretical perspective of the Discourse Analysis (PÊCHEUX, 1969, 1975), we intend to analyze the meaning effects produced by the law $n^{\circ} 11.340 / 2006$, the Law of Maria da Penha, which approaches in its text considerations that allow the applicability of this social normative instrument to Trans individuals (transsexuals and transgenders) and the Bill $n^{\circ}$ 8.032/2014, by Jandira Feghali, which amplifies the protection to these individuals. We aim to reflect on the way issues related to genders and sexualities are applied to the juridical discourse and are concerned not only about the cisgender woman, but about the transsexual woman as well, although the transvestite is erased/silenced. Our goal with this proposal is to realize how the Law and the Bill understand and define "sexual orientation", "gender", "woman", "transsexual" and "transgender", analyzing how the juridical discourse can impose silencing - in this case of transvestites - to the individuals, more than securing their rights.
\end{abstract}

Keywords: The Law of Maria da Penha; The Bill no 8.032/2014; Silencing of the Transvestite.

\section{RESUMEN}

En este trabajo, a partir de la perspectiva teórica del Análisis de Discurso (PÊCHEUX, 1969, 1975), tenemos como propuesta analizar los efectos de sentidos producidos por la Ley nº 11.340 / 2006, Ley Maria da Penha, la

\section{Submetido em: 18/01/2019 Aceito em: 14/02/2019 Publicado em: 01/06/2019}

1 Doutoranda em Estudos Linguísticos no Programa de Pós-Graduacão em Estudos da Linguagem da Universidade Federal do Mato Grosso, Mestre em Letras pela Universidade Estadual do Oeste do Paraná, Graduada em Pedagogia, Ciências Sociais e Letras, com especialização em Educação Especial: Deficiências Múltiplas, em Educação do Campo, ambas pela Faculdade de Educação e Tecnologia da Região Missioneira FETREMIS, e Especialização em Docência no Ensino superior pelo Centro Universitário Barão de Mauá. Atuando desde 2012 na Rede Estadual de Educação do Paraná. Pesquisadora da área de Análise de Discurso e Linguística Aplicada, com ênfase nas Teorias do Discurso, Teorias de Gênero e o Transfeminismo. 


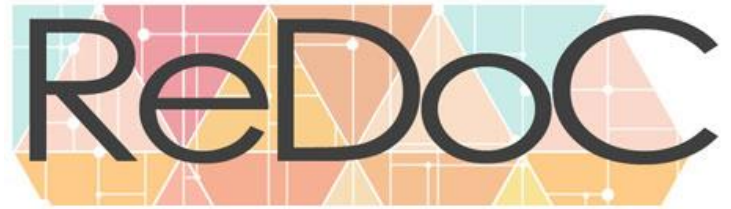

Revista Docência e Cibercultura

cual trae en su texto consideraciones que permiten la aplicabilidad de ese instrumento social normativo a los sujetos trans (transexuales y transgéneros) y el Proyecto de Ley $n^{\circ} 8.032$ / 2014, de Jandira Feghali, que amplía la protección para esos sujetos. Objetivamos reflexionar acerca del modo en que las cuestiones relativas a los géneros y las sexualidades se ponen en funcionamiento en el discurso jurídico y dicen no sólo acerca de la mujer cisgénera, sino también de la mujer trans, aunque la travesti sea en esas legislaciones apagada / silenciada. Nuestra finalidad, con esta propuesta, es percibir cómo la Ley y el Proyecto de Ley comprenden y definen "orientación sexual", "género", "mujer", "transexual" y "transgénero", analizando cómo el discurso jurídico puede, muchas veces, imponer silencios - en este caso con los travestis - a los sujetos, más que garantizar sus derechos.

PALABRAS CLAVE: Ley Maria da Penha; Proyecto de Ley no 8.032 / 2014; Silenciamiento de travesti.

\section{DIZERES INICIAIS}

Neste trabalho, a partir da perspectiva teórica da Análise de Discurso (PÊCHEUX, 1969, 1975), tenho como proposta analisar os efeitos de sentidos produzidos em alguns recortes da Lei ${ }^{\circ} 11.340 / 2006$, Lei Maria da Penha, a qual traz em seu texto considerações que permitem a aplicabilidade desse instrumento social normativo aos sujeitos Trans (transexuais e transgêneros), e do Projeto de Lei $n^{\circ}$ 8.032/2014, de Jandira Feghali, que amplia a proteção para esses sujeitos.

Tenho por objetivo refletir acerca do modo como as questões relativas aos gêneros e às sexualidades são colocadas em funcionamento no discurso jurídico e dizem não só a respeito da mulher cisgênera, como também da mulher trans e evidenciando como a travesti está nessas legislações silenciada.

A Lei $n^{\circ}$ 11.340/2006 assim se enuncia: "Toda mulher - independentemente de classe, raça, etnia, orientação sexual, renda, cultura, nível educacional, idade e religião - goza dos direitos fundamentais inerentes à pessoa humana, sendo-lhe asseguradas as oportunidades e facilidades para viver sem violência, preservar sua saúde física e mental e seu aperfeiçoamento moral, intelectual e social" e, em seu artigo $5^{\circ}$, adverte que "As relações pessoais enunciadas neste artigo independem de orientação sexual".

Na Lei, embora diversos juristas entendam que a mulher trans está sendo contemplada, não há essa materialização (linguística) escrita no instrumento legal. Diferentemente do Projeto de Lei $\mathrm{n}^{\circ}$ 8.032/2014 que ressalta: “As relações pessoais enunciadas neste artigo independem de orientação sexual e se aplicam às pessoas transexuais e transgêneros que se identifiquem como mulheres".

Minha finalidade, com esta proposta, é perceber como a Lei e o Projeto de Lei colocam em funcionamento dizeres sobre os sujeitos "transexual" e "transgênero", analisando como o discurso jurídico pode, muitas vezes, impor silenciamentos a esses sujeitos, mais do que garantir seus direitos. Neste trabalho, analiso especificamente dois recortes dos referidos instrumentos legais. 


\section{UM POUCO DA TEORIA}

Orlandi afirma que "o real da significação é o silêncio. E como meu objeto de reflexão é o discurso, chego á outra afirmação que sucede essa: o silêncio é o real do discurso" (ORLANDI, 2007, p.29). Desse modo, conforme a autora (ORLANDI, 2007, p. 29), o homem está condicionado a significar, portanto, com ou sem palavras este está sujeito á interpretação. Mesmo quando o sujeito silencia ou é silenciado - seja pelo por outro sujeito ou por alguma instituição - este está produzindo sentido e significados.

A autora ainda traz considerações sobre as formas de esquecimento, e diz sobre o esquecimento $\mathrm{n}^{\mathrm{o}} 2$ "que é da ordem da enunciação: ao falarmos, o fazemos de uma maneira e não de outra, e, ao longo de nosso dizer, formam-se famílias parafrásticas que indicam que o dizer sempre podia ser outro" (ORLANDI, 2015, p.33), e sobre o esquecimento $\mathrm{n}^{\circ} 1$ "o outro esquecimento é o esquecimento número um, também chamado esquecimento ideológico: ele é da instância do inconsciente e resulta do modo pelo qual somos afetados pela ideologia"(ORLANDI, 2015, p.33).

Portanto, o esquecimento $\mathrm{n}^{\mathrm{o}} 2$ fala sobre as palavras enunciadas, as quais são utilizadas para dizer sobre algo, mas que podem produzir outros sentidos, enquanto o esquecimento $\mathrm{n}^{\mathrm{o}} 1$, que está condicionado ao inconsciente, reproduz determinado discurso em função de uma determinada ideologia, e como esta nos afeta enquanto sujeito.

Nos recortes selecionados para este artigo, está reforçada a ideia que esse sujeito não sabe sobre si, e que este não é capaz de dizer sobre si, constando um silenciamento do sujeito trans, que é dito por todos, menos por ele mesmo, em função de ideologias que constituem a sociedade,

Constata-se, com efeito, que o sujeito não pode penetrar conscientemente na zona $\mathrm{n}^{\circ} 2$ e que ele o faz em realidade constantemente por um retorno de seu discurso sobre si, uma antecipação de seu efeito, e pela consideração da defasagem que aí introduz o discurso de um outro. $\mathrm{Na}$ medida em que o sujeito se corrige para explicar a si próprio o que disse, para aprofundar "o que pensa" e formulá-lo mais adequadamente, pode se dizer que esta zona $\mathrm{n}^{\circ} 2$, que é a dos processos de enunciação, se caracteriza por um funcionamento do tipo pré-consciente/consciente. Por oposição, o esquecimento $\mathrm{n}^{\mathrm{o}} 1$, cuja zona é inacessível ao sujeito, precisamente por esta razão, aparece como constitutivo da subjetividade na língua. Desta maneira, pode adiantar que este recalque (tendo ao mesmo tempo como objeto o próprio processo discursivo e o interdiscurso, ao qual ele se articula por relações de contradição, de submissão ou de usurpação) é da natureza inconsciente, no sentido 


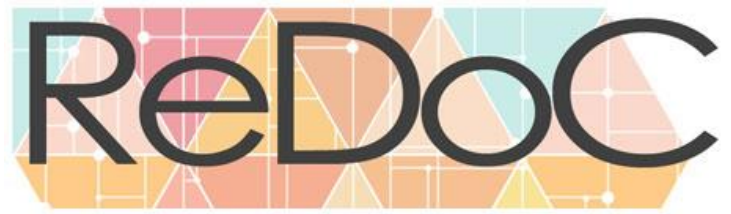

Revista Docência e Cibercultura

em que a ideologia é constitutivamente inconsciente dela mesma. (PÊCHEUX, FUCHS,1997,p.177)

Pêcheux e Fuchs me fazem refletir sobre a conceituação dos esquecimentos, dizendo que o esquecimento $\mathrm{n}^{\mathrm{o}} 2$ é aquele da ordem do que pode ser enunciado, e porque é enunciado de tal forma, com aquelas palavras e não outras.

A exemplo do que foi dito no parágrafo anterior a palavra "tratamento", para se referenciar ao processo transexualizador do sujeito, dá um sentido de enfermidade, uma vez que a transexualidade se encontrava até o início de 2018 no rol de doenças relacionadas a transtornos mentais sobre a sexualidade, "o esquecimento número 2" designa a zona em que o sujeito enunciador se move, em que ele constitui seu enunciado, colocando as fronteiras entre o "dito" e o rejeitado, o "não-dito"” "(MALDIDIER, 2003, p.42).

Já sobre o esquecimento $\mathrm{n}^{\mathrm{o}} 1$ que é da ordem do inconsciente "no "esquecimento número 1 " o sujeito "esquece", ou em outras palavras, recalca que o sentido se forma em um processo que lhe é exterior: a zona do "esquecimento número 1" é, por definição, inacessível ao sujeito"(MALDIDIER, 2003, p.42), e, por isso, é constituído no campo do ideológico, e como dito anteriormente a transexualidade era considerada doença, por isso, está condicionada ao discurso médico patologizante e o jurídico que pune e adia a legalidade para as demandas destes sujeitos.

Ainda existe outro conceito bastante utilizado que podemos atribuir ao se referir á travestis e transexuais, a Formação Imaginária, ou seja, as imagens ou ideais construídos socialmente sobre aquele sujeito, ou o que se espera dele/dela enquanto um corpo que produz sentidos.

As Formações Imaginárias estão relacionadas com os mecanismos que possibilitam o funcionamento do discurso. "Assim não são os sujeitos físicos nem os seus lugares empíricos como tal, isto é, como estão inscritos na sociedade, e que poderiam ser sociologicamente descritos, que funcionam no discurso, mas suas imagens que resultam de projeções" (ORLANDI, 2015, p.38).

Sobre as formações imaginárias, Pêcheux afirma que:

Nossa hipótese é que esses lugares estão representados nos processos discursivos em que são colocados em jogo. Entretanto, seria ingênuo supor que o lugar como feixe de traços objetivos funciona como tal no interior do processo discursivo; ele se encontra aí representado, isto é, presente, mas transformado; em outros termos, o que funciona nos processos discursivos é uma série de formações imaginárias que designam o lugar que A e B se atribuem cada um a si e ao outro, a imagem que eles se fazem de seu próprio lugar e do lugar do outro (PÊCHEUX, 1997, p. 82). 
Essas são as imagens que sujeito A e sujeito B fazem de si; a imagem que fazem um do outro são constituídas pelo inconsciente:

\begin{abstract}
As condições de produção implicam o que é material (a língua sujeita a equívoco e a historicidade), o que é inconstitucional (a forma-social em sua ordem) e o mecanismo imaginário. Esse mecanismo produz imagens dos sujeitos, assim como todo objeto do discurso, dentro de uma conjuntura sócio-histórica. Temos assim a imagem da posição sujeito locutor (quem sou eu para lhe falar assim?) mas também da posição sujeito interlocutor (quem é ele para me falar assim, ou para que eu lhe fale assim?), e também a do objeto do discurso (do que estou lhe falando, do que ele me fala?). É pois todo um jogo imaginário que preside a troca de palavras. E se fazemos intervir a antecipação, este jogo fica ainda mais complexo pois incluirá: a imagem que o locutor faz da imagem que seu interlocutor faz dele, a imagem que o interlocutor faz da imagem que ele faz do objeto do discurso e assim por diante. (ORLANDI, 2015, p.38)
\end{abstract}

Para melhor esboçar as formações imaginárias, trago uma sequência discursiva, selecionada das transcrições ${ }^{2}$ da série "Quem sou eu?", série esta que circulou no programa Fantástico da rede Globo de televisão, durante quatro domingos consecutivos entre os meses de março e abril de 2017 e que abordou a transexualidade em diferentes aspectos:

SD 010 Entrevistada mulher trans 2: A parte mais difícil da infância é que eu já sabia que era mulher, mas as pessoas não me viam assim.

Na SD 010, a qual traz a fala de uma mulher transexual com o nome não identificado, a entrevistada diz: "era mulher, mas as pessoas não me viam assim". A locutora (Entrevistada mulher trans2) exemplifica, assim, o conceito de formação imaginária no enunciado destacado por mim, na SD010, uma vez que retoma a memória da imagem do que é ser uma mulher (imagem que ela faz de si) ao dizer "era mulher"; recupera a imagem que as pessoas formulam sobre ela (imagem que o outro faz dela) ao dizer "mas as pessoas não me viam assim", que funciona como um mecanismo de antecipação:

Em toda língua há regras de projeção que permitem ao sujeito passar da situação (empírica) para a posição (discursiva). O que significa no discurso são essas posições. E elas significam em relação ao contexto sócio-histórico e a memória (o saber discursivo, o já-dito) (ORLANDI, 2015, p.38).

Esse mecanismo imaginário produz imagens dos sujeitos, assim como do objeto do discurso, dentro de uma conjuntura sócio-histórica. De acordo com Orlandi (2002, p. 42):

\footnotetext{
2 As transcrições desta série foram feitas por mim. Elas fazem parte dos anexos da minha dissertação de mestrado, ao total são 277 SDs.
} 
O imaginário faz necessariamente parte do funcionamento da linguagem. Ele é eficaz. Ele não "brota" do nada: assenta-se no modo como as relações sociais se inscrevem na história e são regidas, em uma sociedade como a nossa por relações de poder. [A imagem] se constitui nesse confronto do simbólico com o político, em processos que ligam discursos e instituições.

Portanto, as formações imaginárias estão permeadas pelas relações de poder e por sentidos estabilizados acerca dos sujeitos. Essas formações estão condicionadas às imagens que são produzidas em um determinado contexto histórico-social, pois o imaginário está presente, é constitutivo e essencial no funcionamento da linguagem.

Há, como vou mostrar em minhas análises, diferentes imagens que a sociedade faz do sujeito trans, que esse sujeito faz de si e da sociedade, as quais estão em constante funcionamento nas relações sociais.

"Enquanto corpo simbólico, corpo de um sujeito, ele é produzido em um processo que é um processo de significação, onde trabalha a ideologia, cuja materialidade específica é o discurso" (ORLANDI, 2012, p.16). Essa afirmação de Orlandi sobre o corpo do sujeito e sua constituição como processo de significação traz luz às nossas reflexões sobre o sentido de corpo e o corpo produzindo sentidos, em um processo discursivo de produção de sentidos, o que está relacionado á representação do corpo do/da travesti/transexual.

As questões relacionadas ao corpo do sujeito transexual/travesti são precursoras de várias discussões e decisões que envolvem esses sujeitos. Nessa perspectiva, sobre o corpo e a sua constituição como processo de (re)significação dos sujeitos, Orlandi nos diz:

Levei em conta, ao pensar o sujeito, em sua materialidade, significando-o e significando-se no espaço urbano, que havia uma especificidade em seu processo de significação que se relacionava fortemente ao seu corpo. Havia, por exemplo, marcas produzidas pela inserção do sujeito com sua materialidade em um outro espaço de significação: o urbano e o rural. A interpelação do indivíduo em sujeito pela ideologia produz uma forma sujeito histórica com seu corpo. Há, eu diria, uma forma histórica (e social) o corpo, se pensamos o corpo do sujeito. (ORLANDI, 2012, p.17)

Vejamos a seguinte sequência discursiva também retirada das transcrições da série "Quem sou eu?":

SD 121 Andreia mulher trans: eu tinha né, algumas paixões minhas, que não dariam certo né, agora que eu realmente já me sinto, né? Relativamente confortável com meu corpo, eu já me sinto muito mais preparada pra ter um relacionamento, eu não teria mais o mesmo desconforto que eu teria antes em deixar alguém tocar o meu corpo realmente. 


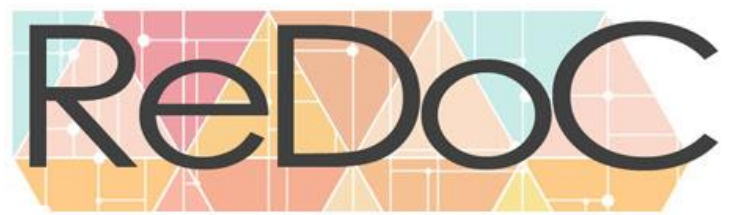

Revista Docência e Cibercultura

Na SD 121, na parte destacada "Relativamente confortável com meu corpo", Andreia, uma mulher transexual, fala sobre a questão de estar bem com o próprio corpo, o qual ela foi constituindo num processo histórico-ideológico-social, que a representa e também diz sobre ter um determinado tipo de corpo para que alguém possa tocar - convencionado como feminino, socialmente.

Ao utilizar-se da palavra "relativamente", ela está se comparando, se relacionando a algo, nesse caso, a um padrão, portanto, relativamente, ao que é esperado para o corpo feminino, ela estaria confortável: "todas as funções do corpo feminino são controladas e reguladas pelo patriarcado, transformando o corpo em um objeto de exploração (sexual, econômica, familiar)" (PEREIRA, 2017, p.99).

Esse viés da exploração é abordado pela série, uma vez que os próprios sujeitos entrevistados fazem relatos sobre a prostituição, como principal alternativa para a sobrevivência, que se torna um meio de exploração desse sujeito, um corpo que é vendido e, consequentemente, explorado.

Portanto, partindo desse conceito, analisaremos em nosso trabalho como o corpo do sujeito trans é colocado em evidência para dizer sobre esse sujeito e para fazer com que esse sujeito também diga de si e do modo como relaciona (seja, algumas vezes, por intervenções cirúrgicas) com esse seu corpo que nem sempre é reconhecido e legitimado na sociedade, a qual tem a heteronormatividade como estrutura significante.

\section{A LEI MARIA DA PENHA E O PROJETO DE LEI 8.032/2014: DIREITOS TRANS?}

A Lei 11.340/06, conhecida popularmente como Lei Maria da Penha, ganhou este nome em homenagem a Maria da Penha Maia Fernandes, uma biofarmacêutica que durante vinte anos foi violentada pelo marido, um professor universitário. Após duas tentativas de homicídio e o violentador ainda estar impune, o caso ganhou repercussão internacional e, a partir da intervenção de ONGs, chegou à Comissão Interamericana de Direitos Humanos, a qual cobrou uma tomada de posição da justiça brasileira, sendo, portanto, esse um marco inicial para a criação da "Lei Maria da Penha".

Porém, somente depois de vinte anos dos primeiros registros de violência sofrida por Maria da Penha é que essa lei passou a vigorar. Portanto, só em setembro de 2006, a lei finalmente entrou em funcionamento, e, a partir daí, o crime de violência contra as mulheres foi regulamentado na legislação nacional brasileira 
Já em 2014, a Deputada Jandira Feghali ${ }^{3}$ propôs ao Congresso Nacional um Projeto de Lei que amplia o público atendido pela Lei Maria da Penha, contemplando as mulheres transexuais e transgêneros. Projeto que traz em seu texto de justificativa a afirmação e caracterização de quem é o sujeito transexual e transgênero, respaldada no discurso médico, seguido de uma justificativa social.

Esse projeto proposto pelo Deputada Jandira Feghali é uma medida normativa legal de prevenção e de violência para com o público trans, e sua existência justifica-se pela alto índice de violência para com o(s) sujeito(s) trans, tendo em vista que o Brasil é o país que ocupa o topo no ranking dos crimes por transfobia.

Essa proteção, condicionada ao gênero, está presente também no texto do Artigo $5^{\circ}$ da Lei Maria da Penha, "Para efeitos desta Lei, configura violência doméstica e familiar contra a mulher qualquer ação ou omissão baseada no gênero que lhe cause morte, lesão, sofrimento físico, sexual ou psicológico e dano moral ou patrimonial: (...)", logo, o texto da Lei deixa bem claro que será considerada a violência á ação que estiver relacionada ao gênero, no entanto, não fala, qual é o gênero, diferentemente do Projeto de Lei em que essa delimitação ocorre.

Neste trabalho, tendo como perspectiva teórica a Análise de Discurso pecheutiana, foram selecionadas duas Sequências Discursivas (doravante SD), sendo uma pertencente à Lei Maria da Penha e a outra ao texto sobre o Projeto de Lei, de Jandira Feghali. Meu intuito com a breve análise dessas sequências é compreender como sentidos sobre a mulher (cis e trans) e a violência são postos em funcionamento.

Na primeira sequência, temos:

SD (01): O Projeto em debate visa a ampliar a proteção de que trata a Lei no 11.340, de 7 de agosto de 2006 - Lei Maria da Penha - às pessoas transexuais e transgêneros que se identifiquem como mulheres. Há uma polêmica discussão na doutrina e na jurisprudência sobre quem pode ser vítima de violência doméstica. Diante dessa questão, cabe investigar qual seria o verdadeiro objetivo da Lei Maria da Penha. Assim sendo, constata-se que o real escopo dessa Lei é prevenir, punir e erradicar a violência doméstica e familiar contra a mulher, não por razão do sexo, mas em virtude do gênero. (PROJETO DE LEI 8.032/2014.2014. p.2. grifos meus).

\footnotetext{
${ }^{3}$ É uma médica brasileira, natural de Curitiba - Paraná, filiada ao Partido Comunista do Brasil (PCdoB), construiu carreira política pelo Estado do Rio de Janeiro.
} 


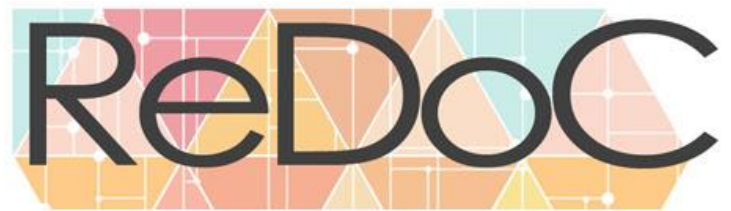

Revista Docência e Cibercultura

Observando o primeiro grifo no recorte do Projeto de Lei, "transexuais e transgêneros", não encontramos o sujeito travesti na redação desse texto, logo, esse sujeito é silenciado/apagado do discurso, pois não aparece, não consta no texto do projeto.

Valendo-se do conceito de formação imaginária, tal como teorizado por Orlandi (2013, p. 41), sendo parte do funcionamento da linguagem e assentando-se no "modo como ás relações sociais se inscrevem na história e são regidas em uma sociedade como a nossa, por relações de poder", é possível dizer que o sujeito travesti não seja socialmente aceito/visto como imagem de mulher e representação do feminino, uma vez que este se traveste como do sexo biológico exposto, ou seja, mesmo que este esteja "caracterizado" como mulher, perante a lei não seria considerada/julgada como tal, mas em função de seu sexo biológico que estaria atrelado ao conceito de masculino, e por assim ser, tratar-se-ia de um homem, e não de uma mulher, perante a lei.

Ao olhar para o segundo gripo destacado na SD 01, "cabe investigar qual seria o verdadeiro objetivo da Lei Maria da Penha", é curioso como esse texto retoma a ideologia de superioridade do homem em relação á mulher, o patriarcado, pois ao se dar conta que há uma lei específica para proteger a mulher das violências que esta poderá vir a sofrer, em função dos atos de um homem, o homem sente a necessidade de criar mecanismos que possibilitem sua transposição á esta lei, e por isso vê a necessidade de investigação sobre qual o propósito de tal instrumento legal, quando este especifica seu objeto de proteção que é a mulher, limitando as mulheres amparadas por esta lei, silenciando e esquecendo algumas mulheres, mas colocando claramente seu objeto protetivo a mulher, então ao formular este texto - cabe investigar qual seria o verdadeiro objetivo da Lei Maria da Penha - ele se volta contra á mulher e não contra o instrumento legal.

No terceiro grifo, destacamos um trecho do texto que fala sobre "violência doméstica e familiar contra a mulher", o que nos permite compreender que a mulher que não se encontra no âmbito doméstico, ou no seio da sua família, não será amparada por esse instrumento legal.

Ao pensar e refletir sobre esta infeliz realidade, a população Trans ${ }^{4}$, que trabalha na prostituição e tem como única fonte de renda o dinheiro que consegue com essa prática, pois ás empresas em sua grande maioria não está aberta á contratação de pessoas transexuais, e assim tem a sua maioria populacional trabalhando no ramo da prostituição, não seria contemplada, porque estão inscritas em um lugar que não condiz com aquele lugar que a lei e o projeto colocam em seus textos.

\footnotetext{
${ }^{4}$ TRANS no dicionário significa, além dê. Para este artigo, entenda-se Trans como todas aquelas pessoas que se identificam como mulher, além das convenções sociais da sociedade heteronormativa, sejam elas transexuais, travestis, transgêneros.
} 
A mulher trans que está em condição de prostituição, estando nas ruas, não se encontra contemplada na esfera doméstica e nem familiar, assim, o seu lugar (ruas, casas noturnas, boates, etc.), não é o lugar contemplado pela Lei.

No quarto grifo da SD 01, "em virtude do gênero", os conceitos de mulher contemplados pelo Projeto de Lei não se validam baseados no "sexo", mas sim pelo gênero. Logo, a primeira impressão é de que o determinismo biológico de sexo/genitália masculino ou feminino é excluído, porém, o conceito de gênero sobre o qual o texto traz é uma construção da sociedade, ou seja, esse "gênero" que a lei aponta é o gênero baseado em parâmetros convencionados pela sociedade heteronormativa, logo, esses sujeitos trans, não estariam sendo contemplados por este instrumento legislativo, pois são vistos pela sociedade como exceções á regra do ser masculino ou feminino, não podendo haver a ocorrência de algo que destoe desse modo de ser, homem ou mulher, determinado biologicamente e condicionados á padrões construídos socialmente para cada sexo, seja masculino ou feminino, de maneira que não são aceitos na sociedade outras formas do ser.

Já, na SD2, temos:

SD (02): Na interpretação desta Lei, serão considerados os fins sociais a que ela se destina e, especialmente, as condições peculiares das mulheres em situação de violência doméstica e familiar. (LEI MARIA DA PENHA, 2006. art.4. Grifos meus).

Novamente faz parte da sequência discursiva selecionada a lei silenciando quem são as mulheres contempladas por essa lei e o próprio texto dizendo qual é o lugar que a mulher deve ocupar na sociedade - lugar doméstico ou familiar - se esta quiser ser amparada pela lei, caso necessite.

As interpretações que pairam sobre a Lei Maria da Penha sobre o "lugar" que deve ocupar o sujeito amparado por este instrumento legislativo é condizente com o Artigo $4^{\circ}$ da Lei Maria da Penha "na interpretação da lei serão considerados os fins sociais a que ela se destina e, especialmente, as condições peculiares das mulheres em situação de violência doméstica ou familiar".

Portanto, este instrumento legal que visa coibir e prevenir à violência contra a mulher transexual e transgênero, silenciando á travesti, perde a eficácia no caso dos sujeitos trans, uma vez que a maioria da população trans encontra-se em situação de prostituição nas ruas ou em ambientes propícios para o comércio sexual, e não no âmbito familiar e doméstico dito e imposto conforme a Lei. 


\section{DIZERES FINAIS}

Primeiramente, gostaria de destacar dois "lugares" que são retomados na redação da Lei Maria da Penha e na redação do Projeto de Lei, pois é lugar, o qual, segundo o que diz os textos legais, cabe à mulher se esta quiser estar amparada por esse instrumento legislativo: o ambiente doméstico e familiar, assim a mulher que se coloca fora desse padrão e lugar do âmbito doméstico e familiar não está contemplada pela lei, portanto, a mulher que tem funções que diferem de ser/estar no ambiente doméstico e familiar não pode fazer o uso dos direitos previstos na lei.

Por seguinte, em momento algum no texto da Lei Maria da Penha, esta traz a definição a respeito de qual mulher essa lei está falando. Logo, diversas mulheres são silenciadas e, a não serem aquelas que estejam no ambiente doméstico e familiar, as demais estão esquecidas.

Aqui também cabe uma reflexão sobre quem é a mulher que ocupa o ambiente doméstico e familiar, pois esta deve ser detentora de algumas características, tais como: ser branca, ter olhos claros, cabelos claros, ter seios grandes, cintura fina, nádegas grandes, boa estatura e ser saudável (pois será mãe), saber cozinhar, lavar, passar, limpar, e cuidar dos filhos (quando os tiver), aquelas que não se encaixam nesses parâmetros, quase não aparecem nos casos registrados de violência contra a mulher, então quando esta lei foi proposta, quem era a mulher que se pretendia amparar?

Já o Projeto de Lei que visa contemplar os sujeitos transexuais e transgêneros, porém, não deixa claro esta abrangência para o sujeito travesti - talvez este se encaixe como uma categoria na transgeneridade -, novamente limitando os sujeitos que podem/devem ser atendidos por esse instrumento legal, o qual também, assim como a Lei Maria da Penha, limita o lugar que o sujeito deve ocupar/permanecer se este quiser ser amparado pela lei.

Existe uma resistência do jurídico em tornar o sujeito trans um sujeito contemplado pela lei em sua integridade, um sujeito de direito como todos os outros não trans. Esses sujeitos valem-se da legislação vigente, que ampara a grande parte da sociedade que é cisgênera, o que, em vários casos, não aplicar-se-ia aos sujeitos trans, mas isso é usado como instrumento de "justiça" para todos.

Os sujeitos trans precisam, sim, de leis que contemplem e reflitam a sua especificidade de ser quem são, uma vez que a própria sociedade os coloca como diferentes e os exclui; pois bem, que existam leis diferentes para esses diferentes. 
Essa questão legal, da falha do jurídico, reflete-se bem quando se trata de crime de transfobia, pois todos os crimes com esse perfil são noticiados como homicídios, como se não tivessem uma motivação única, que é o fato da vítima ser um sujeito trans.

Novamente reforçando a ideia que a maioria da população trans sobrevive em condição de prostituição e que realizam estas práticas nas ruas, e, por estar em situação de vulnerabilidade total a maioria necessita do amparo desta medida inibidora da violência, porém não serão contempladas por ela.

Mesmo com todos os silenciamentos previstos no texto da Lei Maria da Penha e do Projeto de Lei de Jandira Feghali é preciso reconhecer as mudanças sociais que esses instrumentos normativos causaram na sociedade em relação aos índices de violência - de todas as formas contra a mulher. Porém, ainda há muita luta e resistência para que a(s) mulher(es) possa(m) ocupar lugares que sócio-historicamente "não" cabem a ela, como universidades, política, empresas, entre outros.

Seguiremos resistindo e resistentes.

\section{REFERÊNCIAS}

BENTO, Berenice. O que é transexualidade. 2.ed. São Paulo, SP: Brasiliense, 2012.

CAVALIERI FILHO, Sergio. Programa de Sociologia Jurídica. 13. ed. Rio de Janeiro - RJ.

DIAS, Maria Berenice. Diversidade Sexual e Direito Homoafetivo. 2.ed. São Paulo - SP.

Editora revista dos tribunais, 2014.

GADET, Françoise; HAK, Tony. [1969]. Por uma análise automática do discurso. Uma Introdução à Obra de Michel Pêcheux. Editora da Unicamp, 1997.

MALDIDIER, Denise. A inquietação do discurso - (Re)ler Michel Pêcheux hoje. Tradução Eni P. Orlandi. Campinas, SP, 2003.

ORLANDI, Eni Puccinelli. Análise de Discurso: princípios e procedimentos. $12^{\mathrm{a}}$ Edição, Pontes Editores, Campinas, SP. 2015.

ORLANDI, Eni Puccinelli. Discurso e Texto: formulação e circulação dos sentidos. $4^{\mathrm{a}}$ Edição, Pontes Editores, Campinas, SP. 2012. 


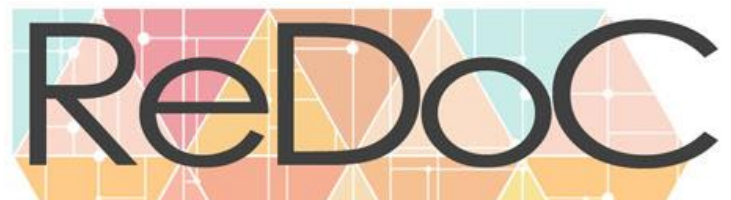

Revista Docência e Cibercultura

PÊCHEUX, Michel. Análise de Discurso: Michel Pêcheux Textos Selecionados: Eni Puccinelli Orlandi. $4{ }^{\text {a }}$ Edição, Pontes Editores, Campinas, SP. 2015.

PÊCHEUX, Michel. Semântica e Discurso: uma crítica à afirmação do óbvio. $4^{\mathrm{a}}$ Ed. Campinas - SP. Editora da Unicamp. 2009.

PEREIRA, Fernanda. CORPOS EM PROTESTO: Análise Discursiva do Movimento FEMEN. 2017. (160 f.). Dissertação (Mestrado em Estudos da Linguagem) - Universidade Estadual do Oeste do Paraná. Cascavel.

http://www.camara.gov.br/proposicoesWeb/prop_mostrarintegra;jsessionid=4ED2CCEEB060 AB5A153FED625CB7E9A3.proposicoesWebExterno1? codteor=1282632\&filename=Tramita cao-PL+8032/2014. Acesso em: 19 ago. 2017

http://www.planalto.gov.br/ccivil_03/_ato2004-2006/2006/lei/111340.htm. Acesso em: 19 ago. 2017

http://www.camara.gov.br/proposicoesWeb/prop_mostrarintegra;jsessionid=C5D4711B50706 F73DE29B00A6F757134.proposicoesWebExterno2?codteor $=1372701 \&$ filename $=$ ParecerCDHM-17-08-2015. Acesso em: 19 ago. 2017

http://www.observe.ufba.br/lei_mariadapenha. Acesso em: 19 ago. 2017. 